Journal of Engineering and Applied Sciences 14 (Special Issue 9): 10632-10637, 2019

ISSN: 1816-949X

(C) Medwell Journals, 2019

\title{
The Effect of Gold Nanoparticles on the Switching Properties of Acrylate Liquid Crystal Polymer
}

\author{
Khalid Al. Ammar and Hammood Faihan Obaid \\ Department of Physics, College of Education for Pure Sciences, \\ University of Babylon, Hillah, Iraq
}

\begin{abstract}
In this research, the effect of gold nanoparticles on the switching properties of acrylate liquid crystal polymer was studied. Five different ratios of gold nanoparticles $(0.07,0.1,0.13,0.16,0.19 \%)$ have been added to a fixed molecular weight of acrylate liquid crystal $\left(1.7 \times 106 \mathrm{~g} \mathrm{~m}^{-1}\right)$. Optical response times $\left(\tau^{\text {on }}\right.$ and $\left.\tau^{\text {off }}\right)$ are affected by the alternating electric field. It has been found that the addition of nanoparticles increases the degrees of glass transition. Also, the conductivity increases by when an electric field is exposed which eventually reduces the time of optical response. By increasing the added nanoparticles we notice an increase in the viscosity of the liquid crystal polymer used while the threshold voltage decreases with the increase of nanoparticles.
\end{abstract}

Key words: Research, liquid, nanoparticles, polymer, conductivity, switching

\section{INTRODUCTION}

In 1888, the Austrian botanist Friedrich Reinzer discovered that "cholesterol reduction" had two melting points (" 178.5 and $145.5^{\circ} \mathrm{C}$ "). At $145.5^{\circ} \mathrm{C}$, the solid crystal dissolved in a cloudy liquid remaining as high as $178.5^{\circ} \mathrm{C}$ where the clouds disappeared, resulting in a clear liquid. It is a unique type of system called liquid crystal (Ammar and Salih, 2017). The only difference between cases of matter (solid, liquid and gaseous) is in the order of their molecules. The particles are arranged in a direct and indirect order and the liquid crystal is the fourth state of matter, occupying specific locations in the grid (Collings and Hird, 1997; Ammar and Salih, 2018). Liquid crystals are characterized by liquidity and long-range arrangement (which contains a defective degree of order of direction and position) (Ammar and Al-Jamal, 2018). Intercellular crystals mediate the degree of molecular arrangement between short-term arrangement and long-term guidance arrangement (Gray and Winsor, 1974). The development of liquid crystals has continued over the past years and still continues today. The development of liquid crystals, introduced in 1960, produced a real explosion of scientific research, often involving chemists and physicists (Pierre-Gilles de Gennes) (Dunmur and Sluckin, 2011; Ammar and Al-Jamal, 2018) liquid crystals are formed in two different ways, one by pure thermal processes and the other by adding solvent crystals without being solid (Gray and Goodby, 1984; Obaid et al., 2016). The first method is called the "thermal method" while those obtained through the second process are called "micro organisms”. Given the geometric composition of mossogenic particles, liquid crystals can be grouped into several types. Liquid crystals derived from rod-shaped molecules ("any axis much longer than other axes") are called "calamities". The phases of the detection molecules (i.e., the molecular axis is much shorter than the other two axes) are referred to as discos. These molecules are called banana molecules in the form of "curved" liquid crystals. Liquid crystals are also derived from some large molecules (such as long chain polymers), typically in solution but sometimes in its pure state known as liquid crystal polymers (Keller et al., 1980; Al-Ammar and Mitchell, 1992). Three categories of thermal crystals can be classified accordingto the amount of temperature-induced change, called heat-induced pathways. "Liquid crystals" appear in form of flat layers and parallel longitudinal axes as the thickness of molecules or molecular length can be random according to the nature of the material). The particles of this layer are characterized by the diagonally movement and non-movement between layers.

The "liquid crystals" of this type have a lower consistency than the toxic phase as the nematode phase are considered to be more flexible. Linear molecules are parallel and not separated in layers. The particles vibrate in an average direction during thermal irritation. Crystalline liquid crystals are in the form of thin layers and thickness of these layer are at one bold length. At the layer level, molecules begin with longitudinal axes. The axes are parallel to each other in one layer (De Gennes and Prost, 1993; Chandrasekhar, 1992; Shao and Zerda, 1998). The possibility of creating new

Corresponding Author: Hammood Faihan Obaid, Department of Physics, College of Education for Pure Sciences, University of Babylon, Hillah, Iraq 
polymer materials by combining the unique properties of low molecular mass crystals with those with high molecular mass has led to a new science of polymeric fluid crystals. There are mesogenic groups in the polymer's structure and composition. These materials of the basic structural units of the system constitute high or supercritical fibers. Second, mesogenic groups by means of appropriate interactive substitutes are linked to a polymer column found in a side chain polymer or comb-like systems. In such a system, the side that contains the mesogenic group has a order parameter based on the strength of the coupling in the structure and can be altered without alignment through an external electrical application or other fields (Al-Ammar et al., 1993). This study concerns the study of the properties of the 1 inks ( $\tau^{\text {on }}$ and $\tau^{\text {off }}$ ) of the polymer-acrylate band with fixed molecular weight when adding different weights of nanoparticles to the polymer. Molecular structure of liquid crystals: liquid crystalline materials are classified into polymers which are high-mass crystalline liquid or monomers which are low-mass crystalline liquid. Many of the molecules formed for common liquid microgases (Donald and Windle, 1992). The state of the liquid crystal depends on several factors such as the ratio of the length of the molecule to its width and the lateral gravity of the peripheral group (Mittal, 2010; Teo and Sun, 2007). The molecules of nematic liquid crystals tend to align parallel to each other. Because of the orientational ordering of the rod-like molecules, the nematic liquid crystals are uniaxially symmetric with the principle axes parallel to the long axes of the molecules. As a consequence, the nematic liquid crystals exhibit an electrical and optical anisotropy. The anisotropy of the physical properties is very important from the viewpoint of not only molecular theory but also practical applications (Yoshida et al., 1985), fluorescence (Yoshida et al., 1981; Abdoh et al., 1984) and Raman scattering (Chingduang et al., 1986).

\section{MATERIALS AND METHODS}

The core of the research involves measuring the switching properties of acrylate liquid crystalline polymer resulting from the application of electric fields. Provides an electric field with a power amplifier supported by a drive function, frequency of $0-30 \mathrm{kHz}$ with a voltage at $0-240 \mathrm{~V}$. The strength of light transmitted through this system is a function of time. After applying thermal and mechanical treatment, the disks are collected into a cell containing a polymer film of thickness of about 10 microns.

The research involves measuring the changes in the key properties of the thin films as well as the compounds resulting from the addition of nanoparticles to liquid crystal acrylate polymer when applying the electric fields. Figure 1 and 2 illustrates the experimental arrangement used in PV measurements. Photovoltaic cells are kept within a temperature-controlled phase. The optical system consists of a polarized polarizer, helium neon and a photovoltaic diode analyzer system; vertically on a modified optical path with voltages in the amplifier. Electric fields are provided with a power amplifier with a frequency range of $0,05-30 \mathrm{kHz}$ to peak voltages at $0-240$ $\mathrm{V}$. The peak voltages applied were measured by using the oscilloscope. The transmitted light intensity was recorded as a function of time using a microcomputer based system around a compatible computer. Figure 2 scheme of the work system.

Switching properties: In this research we used a constant molecular weight, adding five proportions of gold nanoparticles to study the key properties ( $\tau^{\text {on }}$ and $\left.\tau^{\text {off }}\right)$ of liquid crystalline polymers as a function of temperature. Using experimental arrangement, Fig. 1-5 show the variation of light intensity as a function of the voltage applied. For all polymers, the electrode variation is positive. The system wa used to calculate the optical response times. The cell was placed inside the heating box and then the voltage was measured for full guidance. The laser beams coming out of the polarizer were vertical on the longitudinal axis of the model material molecules. This led to the polarization of the laser which is perpendicular to the polarizer. Thus, the analyst passes the laser light with the greatest intensity in the photovoltaic cell. Repeating the act by increasing the voltages and for several samples demonstrated that the intensity of the laser light is statistically insignificant with the increase of the external field voltage applied to the model. The decrease continues until the minimum radiation value which occurs at complete switching is repeated. All samples are repeated to determine the complete routing voltage. The time is then measured for the full rotation. This is the time between the highest intensity of the laser light and its lowest intensity represented the opening time $\left(\tau^{\mathrm{on}}\right)$. Automatic liquid crystal measurement systems (ALCT) are USB-based tools that can be easily connected to desktops and laptops. It is used to measure voltage and time of visual response ( $\tau^{\text {on }}$ and $\tau^{\text {off }}$ ).

HCS302 contains the following features (Instec company): Fast heating. Precise temperature control $\left(200-600^{\circ} \mathrm{C}\right)$ heating and rapid cooling. High sample room, internal covering to improve sample temperature uniformity.

MK1000: “Instec's high-quality MK1000 temperature control is easy to use. It provides accurate temperature control to $0.001^{\circ} \mathrm{C}$ and can optionally control up to four stages. The MK1000 features dual control panels for heating and cooling. The front panel has a $192 \times 128$ pixel display. It provides a standard "USB2.0" connection port with simple computer control.

The MK1000 has the following features: accuracy $\left(0.001^{\circ} \mathrm{C}\right)$. Programming with no computer and it is compatible with all hot and cold instec stages. 


\section{RESULTS AND DISCUSSION}

In this resaerch, the electro-optical properties of the molecular weight $\left(15106 \mathrm{~g} \mathrm{~m}^{-1}\right.$ ) acrylate liquid crystal were studied. After adding five different ratios of gold nanoparticles, we obtained five models (p1-p5). We note that the increase in the addition of gold nanoparticles will decrease the intensity and the values of the voltages and the threshold voltage are reduced by the increase of the gold nanoparticles. As is evident in Fig. 3-9.

We notice that viscosity increases with the increase of gold nanoparticles and also that the conductivity increases, so, the optical response time (opening time $\tau^{\text {on }}$ ) decreases with the increase of gold nanoparticles as shown in Fig. 10-14.

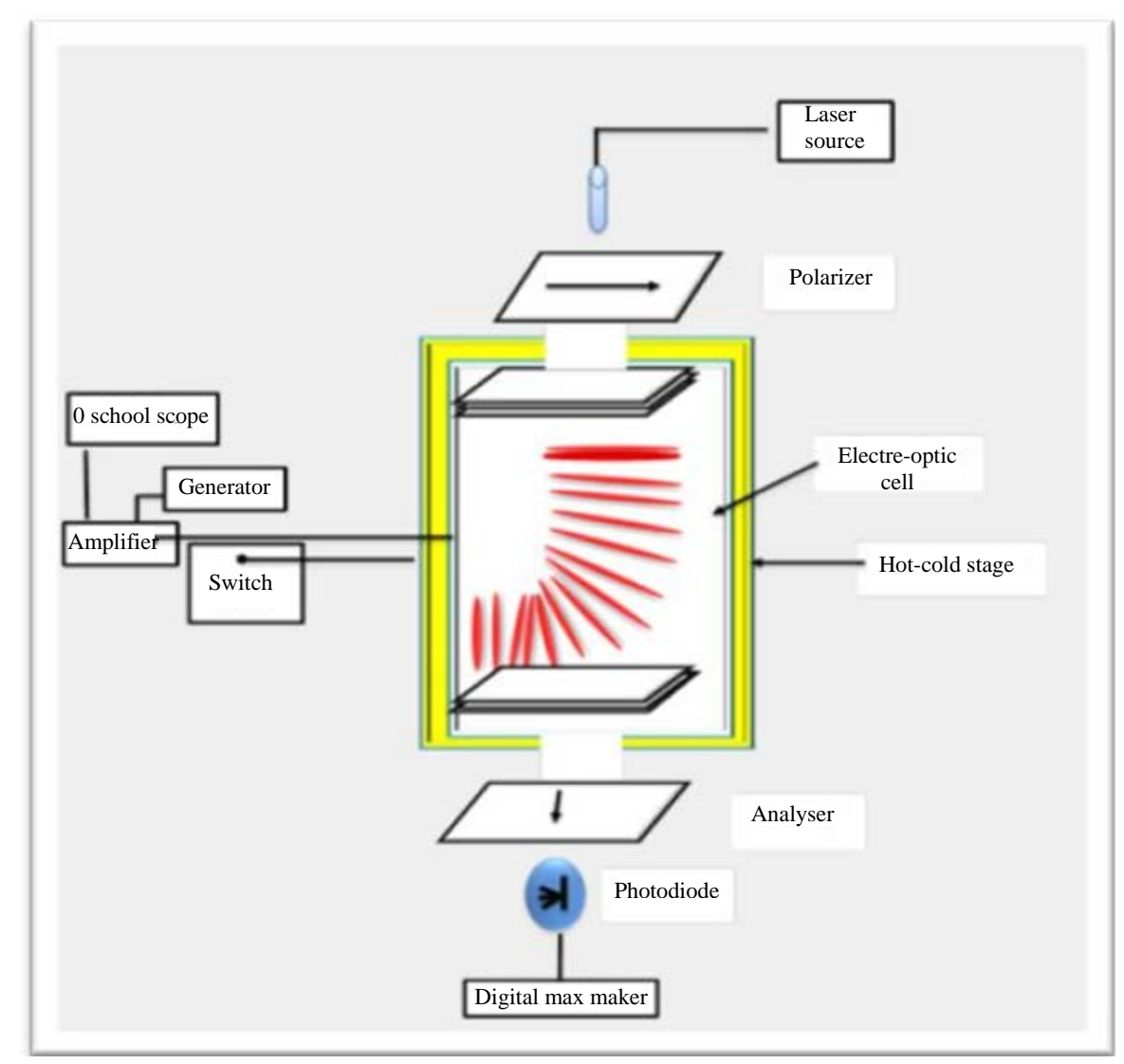

Fig. 1: Layout of the arrangements used in PV measurements

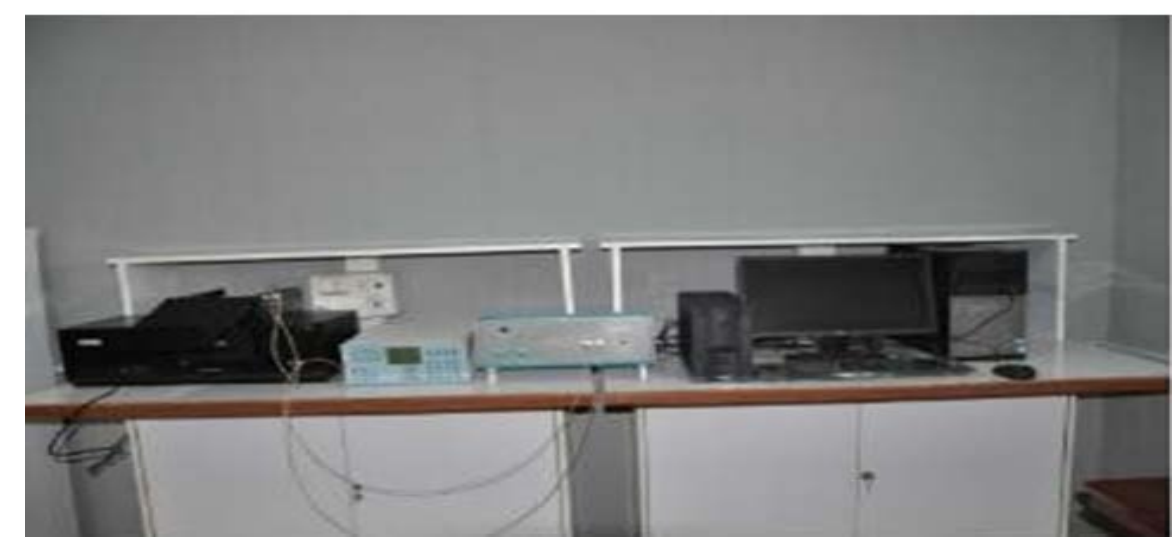

Fig. 2: Picture of a device 


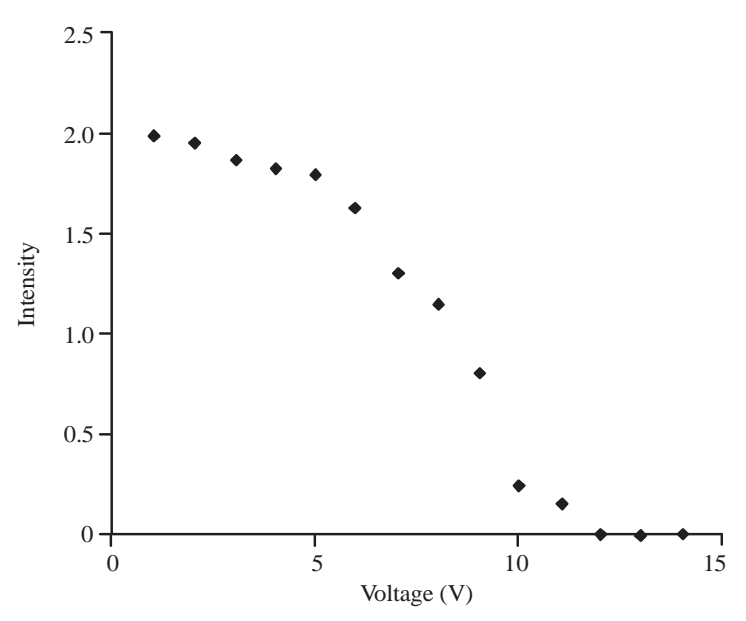

Fig. 3: Volatge variation with natural density of polymer 1 ; Series 1

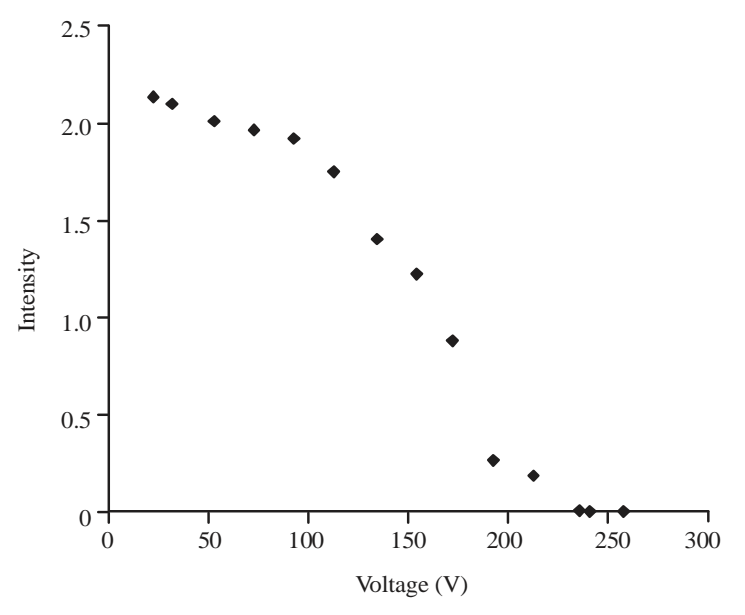

Fig. 4: Volatge variation with natural density of polymer 2; Series 1

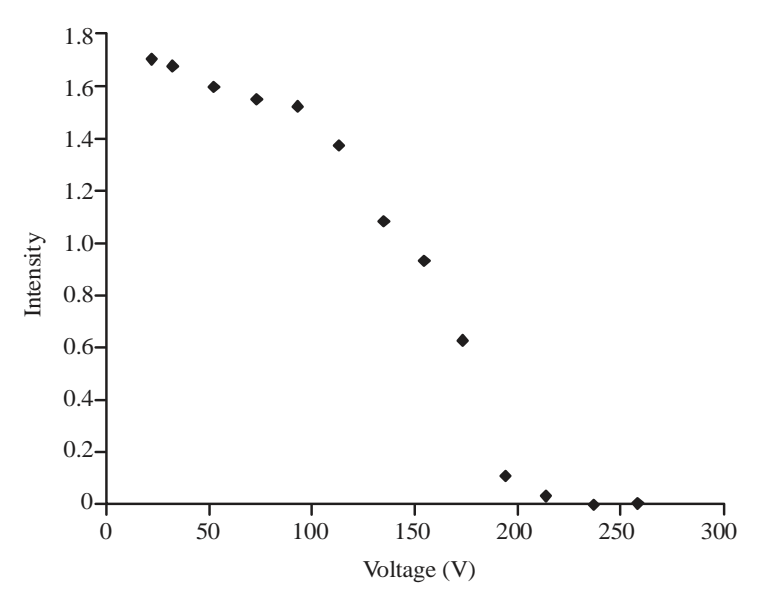

Fig. 5: Volatge variation with natural density of polymer 3; Series 1

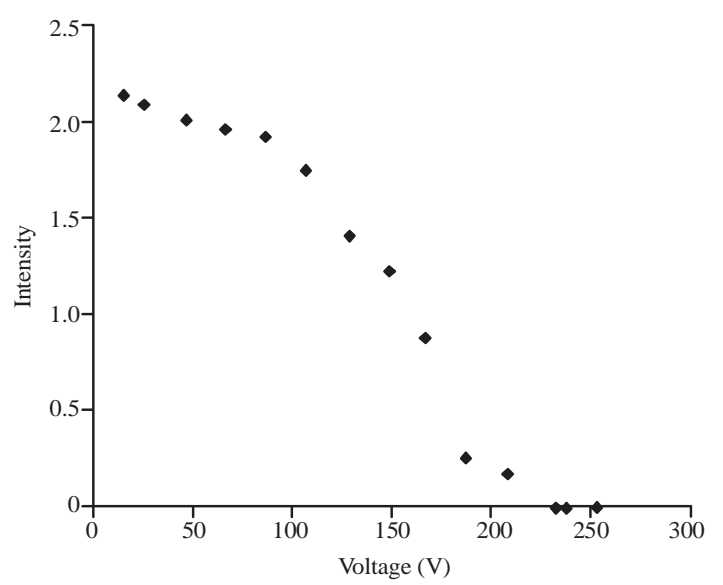

Fig. 6: Voltage variation with natural density of polymer 4; Series 1

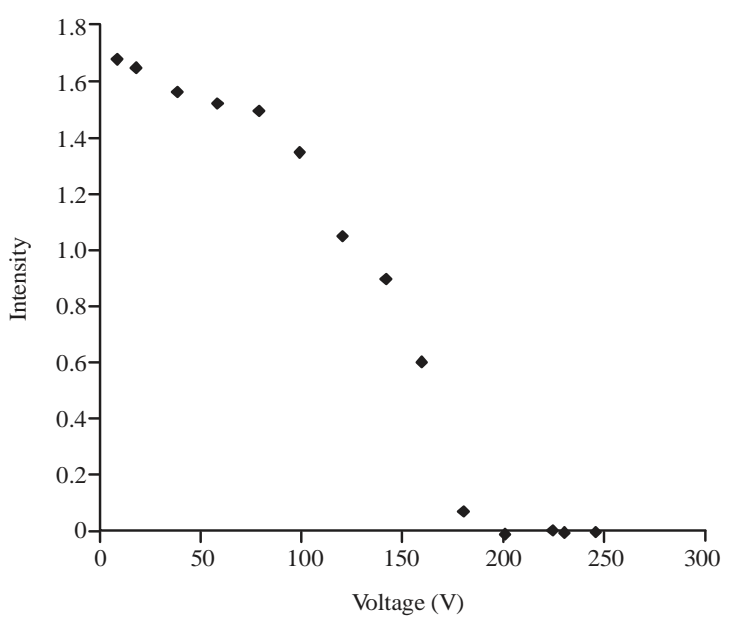

Fig. 7: Voltage variation with natural density of polymar 5; Series 1

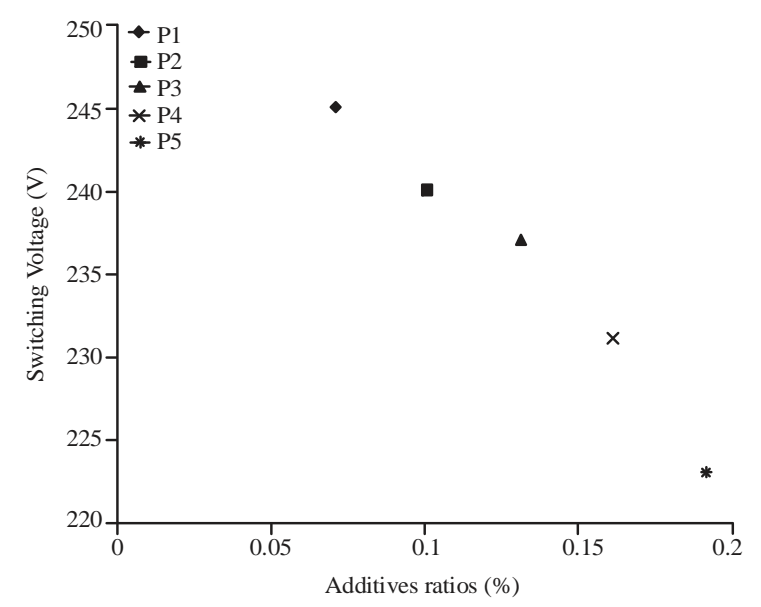

Fig. 8: Switch voltage as a function of the added ratios of all polymers:; Series1 


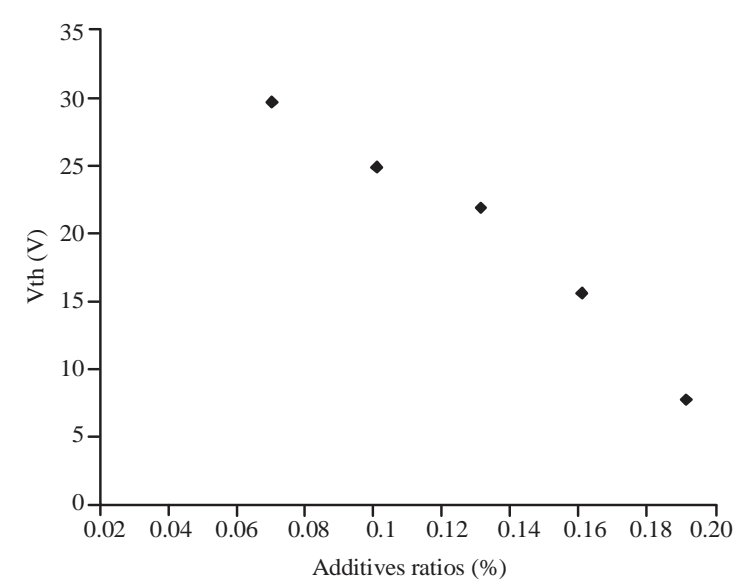

Fig. 9: The voltage threshold as a function of the added ratios

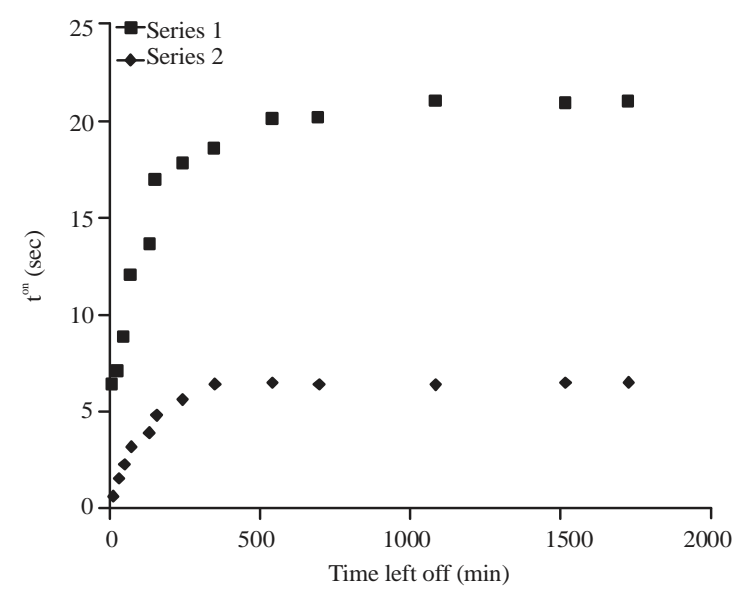

Fig. 10: Switching-on ( $\left.\tau^{\text {on }}\right)$ and time left off $\left(\tau^{\text {off }}\right)$ at constant temperature below $\mathrm{T}_{\mathrm{NI}}$ for polymer 1

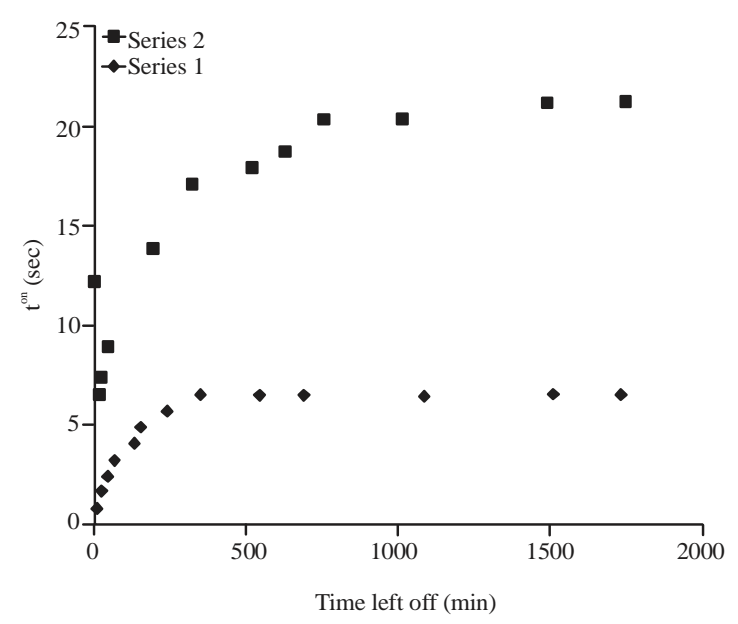

Fig. 11: Switching-on $\left(\tau^{\text {on }}\right)$ and time left off $\left(\tau^{\text {off }}\right)$ at constant temperature below $\mathrm{T}_{\mathrm{NI}}$ for polymer 2

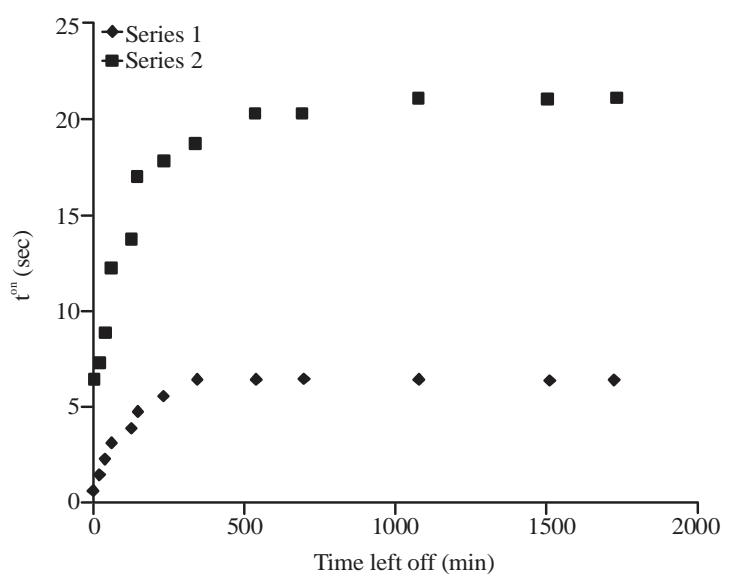

Fig. 12: Switching-on $\left(\tau^{\text {on }}\right)$ and time left off $\left(\tau^{\text {off }}\right)$ at constant temperature below $\mathrm{T}_{\mathrm{NI}}$ for polymer 3

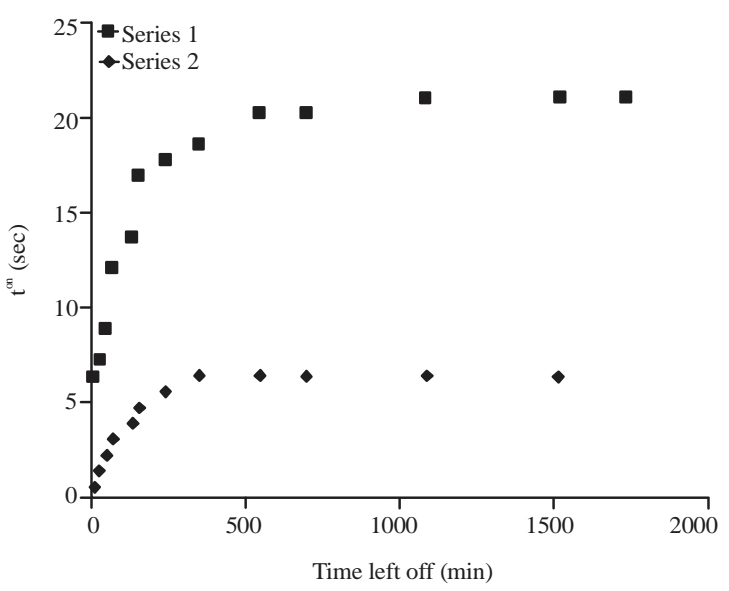

Fig. 13: Switching-on $\left(\tau^{\text {on }}\right)$ and time left off $\left(\tau^{\text {off }}\right)$ at constant temperature below $\mathrm{T}_{\mathrm{NI}}$ for polymer 4

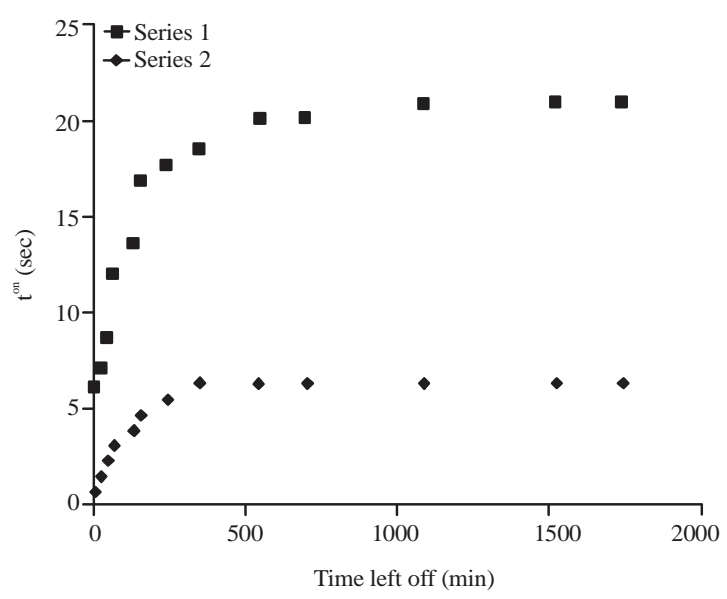

Fig. 14: Switching-on ( $\left.\tau^{\text {on }}\right)$ and time left off $\left(\tau^{\text {off }}\right)$ at constant temperature below $\mathrm{T}_{\mathrm{NI}}$ for polymer 5 


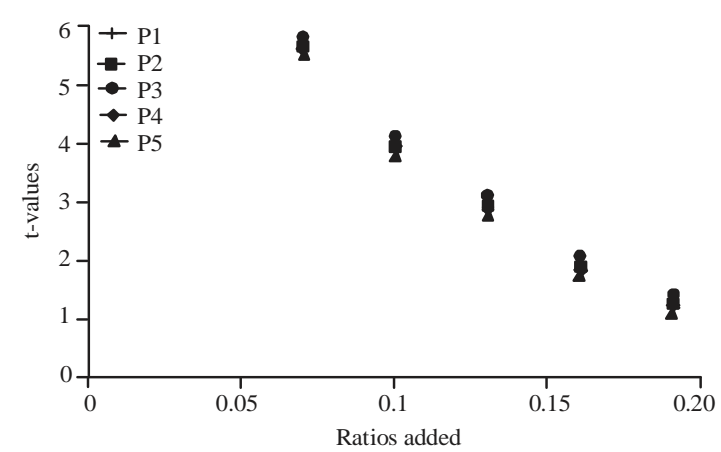

Fig. 15: Switching-on $\left(\tau^{\text {off }}\right)$ as a function of the adding gold ratios for polymer acrylate

\section{CONCLUSION}

In this research, the electro-optical properties of the acrylate liquid crystal were studied after adding five different ratios of gold nanoparticles to a constant molecular weight of the polymer used. The gold nanoparticles were found to have a significant effect on the electro-optical properties of the liquid crystal polymer which reduces the degree of polymer transfer and increases its elasticity as well as increased viscosity which reduces optical response times.

\section{REFERENCES}

AI-Ammar, K.H. and G.R. Mitchell, 1992. Electro-optical properties of liquid crystal copolymers and their relationship to structural order. Polym., 33: 11-21.

Al-Ammar, K.H., M.J. Whitcombe and G.R. Mitchell, 1993. The effect of the molecular weight on the electro-optic properties of methacrylate-based side-chain liquid crystal polymers. Polym., 34: 2060-2064.

Ammar, K.A. and H.A.A.A. Salih, 2017. Effect of BaTiO3 nanoparticles amount addition on electro-optical properties of side chain liquid crystal polymer. Intl. J. Sci. Res., 6: 927-933.

Ammar, K.A. and H.A.A.A. Salih, 2018. Electro-optical properties and effect of BaTiO3 of polysiloxane. J. Eng. Appl. Sci., 13: 9519-9523.

Ammar, K.A. and L.A.O. Al-Jamal, 2018. Influence of ferroelectric nanoparticles on liquid crystal polymer nanocomposites and studying their electro-optic response. J. Eng. Appl. Sci., 13: 10232-10237.

Chandrasekhar, S., 1992. Liquid Crystals. 2nd Edn., Cambridge University Press, Cambridge, UK., Pages: 451.
Chingduang, P., S. Bualek, O. Phaovibul and B. Schrader, 1986. Study of orientation and order of non-mesogenic solutes in liquid crystalline matrix by infrared spectroscopy. Mol. Cryst. Liq. Cryst., 132: 131-141.

Collings, P.J. and M. Hird, 1997. Introduction to Liquid Crystals: Chemistry and Physics. CRC Press, Boca Raton, Florida, USA., ISBN:9780203211199, Pages: 314.

De Gennes, P.G. and J. Prost, 1993. The Physics of Liquid Crystals. 2nd Edn., Clarendon Press, New York, USA., ISBN:9780198520245, Pages: 597.

Donald, A.M. and A.H. Windle, 1992. Liquid Crystalline Polymers. Cambridge University Press, Cambridge, UK., Pages: 310.

Dunmur, D. and T. Sluckin, 2011. Soap, science and flat-screen TVs: A history of liquid crystals. J. Contemp. Phys., 52: 613-614.

Gray, G.W. and J.W. Goodby, 1984. Smectic Liquid Crystals: Textures and Structures. Leonard Hill, Glasgow, Scotland, ISBN:9780249441680, Pages: 162.

Gray, G.W. and P.A. Winsor, 1974. Liquid Crystal \& Plastic Crystals- Preparation. Vol. 1, Ellis Horwood Ltd, Chichester, England, Pages: 314.

Kelker, H., R. Hatz and C. Schumann, 1980. Handbook of Liquid Crystals. Wiley-VCH Verlag GmbH \& Co. KGaA, Weinheim, Germany, ISBN: 9783527254811 , Pages: 917.

Mittal, V., 2010. Optimization of Polymer Nanocomposite Properties. Wiley, Hoboken, New Jersey, USA., ISBN: 978-3-527-32521-4, Pages: 440.

Obaid, A.N., K.H.A. Ammar and F.S. Hashim, 2016. The influence of non-polar group on the properties of poly-siloxanes side chain liquid crystal polymers. J. Univ. Babylon, 24: 727-739.

Shao, Y. and T.W. Zerda, 1998. Phase transitions of liquid crystal PAA in confined geometries. J. Phys. Chem. B, 102: 3387-3394.

Teo, B.K. and X.H. Sun, 2007. Classification and representations of low-dimensional nanomaterials: Terms and symbols. J. Cluster Sci., 18: 346-357.

Yoshida, H., S. Kobinata and S. Maeda, 1985. A study of orientational characteristics of nematics by means of polarized fluorescence. Mol. Cryst. Liq. Cryst., 131: 209-216.

Yoshida, H., Y. Nakajima, S. Kobinata and S. Maeda, 1981. Determination of order parameters in liquid crystal by resonance raman method, 5CB as probed by ß-Carotene. J. Phys. Soc. Japan, 50: 3525-3528. 